\title{
A putative role for homocysteine in the pathophysiology of acute bacterial meningitis in children
}

\author{
Roney Santos Coimbra ${ }^{*}$, Bruno Frederico Aguilar Calegare², Talitah Michel Sanchez Candiani ${ }^{3}$ and Vânia D'Almeida ${ }^{2}$
}

\begin{abstract}
Background: Acute bacterial meningitis frequently causes cortical and hippocampal neuron loss leading to permanent neurological sequelae. Neuron death in acute bacterial meningitis involves the excessive activation of NMDA receptors and p53-mediated apoptosis, and the latter is triggered by the depletion of NAD + and ATP cellular stores by the DNA repair enzyme poly(ADP-ribose) polymerase. This enzyme is activated during acute bacterial meningitis in response to DNA damage induced, on its turn, by reactive oxygen and nitrogen species. An excess of homocysteine can also induce this cascade of events in hippocampal neurons.

The present work aimed at investigating the possible involvement of homocysteine in the pathophysiology of meningitis by comparing its concentrations in cerebrospinal fluid (CSF) samples from children with viral or acute bacterial meningitis, and control individuals.

Methods: Homocysteine and cysteine concentrations were assessed by high-performance liquid chromatography in CSF samples from nine patients with acute bacterial meningitis, 13 patients with viral meningitis and 18 controls (median age: 4 years-old; range: $<1$ to 13) collected by lumbar puncture at admission at the Children's Hospital Joao Paulo II - FHEMIG, from January 2010 to November 2011.

Results: We found that homocysteine accumulates up to neurotoxic levels within the central nervous system of patients with acute bacterial meningitis, but not in those with viral meningitis or control individuals. No correlation was found between homocysteine and cysteine concentrations and the cerebrospinal fluid standard cytochemical parameters.

Conclusions: Our results suggest that HCY is produced intrathecally in response to acute bacterial meningitis and accumulates within the central nervous system reaching potentially neurotoxic levels. This is the first work to propose a role for HCY in the pathophysiology of brain damage associated with acute bacterial meningitis.
\end{abstract}

Keywords: Acute bacterial meningitis, Homocysteine, Neurotoxicity

\section{Background}

Meningitis is the inflammation of the meninges, the protective membranes covering the brain and the spinal cord. According to the etiology, meningitis is classified as viral (VM), also called aseptic meningitis, or bacterial $(\mathrm{BM})$. VM is mainly caused by enteroviruses and is considered to be typically benign, with an auto-limited course being rarely associated to bad prognostic. As

\footnotetext{
* Correspondence: roney.s.coimbra@cpqrr.fiocruz.br

'Biosystems Informatics, Research Center Rene Rachou, FIOCRUZ, Av. Augusto de Lima 1715, Belo Horizonte, MG Zip Code: 30190-002, Brazil Full list of author information is available at the end of the article
}

opposite, acute $\mathrm{BM}$ is ranked among the ten leading causes of death by infectious diseases worldwide [1]. The main etiological agents of BM are Streptococcus pneumoniae, Neisseria meningitidis, and Haemophilus influenzae type b. Despite significant advances in antimicrobial and intensive care therapies in the last decades, mortality rates associated with BM remain as high as $30 \%$, and among the patients who survive the infection, 30 to $50 \%$ have permanent neurological sequelae which include deafness, sensory-motor deficits, seizure disorders, cerebral palsy, mental retardation, and learning impairment associated to neuronal injury [2]. 
The neurological sequelae associated to meningitis are mainly due to neuron loss by necrosis in the cerebral cortex, and by apoptosis in the hippocampal dentate granule cells [3-5]. The cascade of events that triggers neuronal apoptosis during $\mathrm{BM}$ involves the excessive activation of the DNA repair enzyme poly(ADP-ribose) polymerase (PARP) which synthesizes ADP-ribose polymers in response to DNA damage [6]. This process comes at a very high-energy cost depleting NAD + and ATP and thereby causing cell death. PARP may provide a linkage between oxidative DNA damage and apoptosis or necrosis during $\mathrm{BM}$ depending upon the severity of the ATP and NAD + withdrawal. Homocysteine (HCY) is a sulfur amino acid produced from methionine by a methylation cycle [7]. HCY induces neuronal apoptotic death by over stimulating N-methyl-D-aspartate (NMDA) receptors $[8,9]$ and by enhancing the production of free radicals $[10,11]$, two hallmarks of the pathophysiology of acute BM [12-14]. Furthermore, elevated HCY levels in the nucleus of cells may induce DNA strand breaks by disturbing the DNA methylation cycle [15]. Consistent with this hypothesis, Kruman et al. [16] have shown a major role for PARP activation in HCY-induced neuronal apoptosis and increased neuronal vulnerability to excitotoxicity.

Thus, this study aims to investigate the possible involvement of HCY in the pathophysiology of meningitis by comparing its levels and those of cysteine (CYS), another sulfur amino acid two steps downstream to HCY in the same pathway, in cerebrospinal fluid (CSF) samples from infant patients with acute $\mathrm{BM}, \mathrm{VM}$, and control children.

\section{Methods}

$\mathrm{HCY}$ and CYS levels were assessed by high-performance liquid chromatography (HPLC) in CSF samples collected by lumbar puncture from 40 children (median age: 4 years-old; range: $<1$ to 13 years) at admission at the Children's Hospital João Paulo II - FHEMIG, Belo Horizonte, Brazil, with suspected meningitis from January 2010 to November 2011. The cohort comprised: a) nine patients with acute BM confirmed by CSF culture and/or latex agglutination test, being six infected with pneumococci and three with meningococci; b) 13 patients with VM, who had clinical signs of meningitis but presented normal or slightly altered cytochemical parameters in CSF, and negative CSF and blood latex and culture for bacterial pathogens [1]; c) 18 controls subjects attending the hospital because of a suspect of meningitis, but who had no infection of the central nervous system (CNS) or neurodegenerative diseases at the definitive diagnostic. The standard CSF cytochemical parameters assessed for diagnostic purpose immediately after puncture were protein and glucose concentrations, white blood cell count and percentage of polymorphonuclear neutrophils [17]. Patients previously treated with antibiotics, or whose CSF samples contained more than 50 erythrocytes per $\mathrm{mm}^{3}$, indicating blood contamination due to puncture accident, were excluded. All patients included in this study survived meningitis, but one children who had pneumococcal meningitis developed total hearing loss in one ear. An aliquot of the CSF sample was centrifuged at $5.000 \mathrm{rpm}$ for 10 minutes, at $4^{\circ} \mathrm{C}$, and the supernatant was stored at $-80^{\circ} \mathrm{C}$.

$\mathrm{HCY}$ and CYS concentrations in CSF samples were measured by high-performance liquid chromatography (HPLC) with fluorimetric detection after derivatization of sulfur amino acids with fluorescent 7-fluorobenzofurazan4-sulfonic acid as previously published [18]. Calibration curves were linear up to $200 \mu \mathrm{M}$ and $800 \mu \mathrm{M}$ for homocysteine and cysteine, respectively. The limit of detection for homocysteine was $0.16 \mu \mathrm{M}$. For statistical analysis, $\mathrm{HCY}$ and CYS concentrations below the detection limit of the method were arbitrarily assigned to zero.

The variances of medians of all groups were compared using the Kruskal-Wallis test and, subsequently, pairs of groups were compared using the Dunn's test. Correlations were tested using the Spearman's test. The threshold for statistical significance was $\mathrm{p}<0.05$. These statistical analyses were performed with the package GraphPad Prism 5.01 (GraphPad Software, Inc., La Jolla, CA, USA).

This study was approved by the Brazilian Committee for Ethical Research (process number: 25000.199054/2008-18). The guardians of all patients were informed about the study and signed a consent form.

\section{Results and discussion}

The HCY and CYS medians of the three groups varied significantly ( $\mathrm{p}<0.005)$. HCY and CYS concentrations were increased in the CSF of patients with BM, regardless of the pathogen when compared to controls or patients with VM (Table 1). The median concentration of $\mathrm{HCY}$ in the CSF of patients with BM $(0.69 \mu \mathrm{M})$ was higher than the lowest concentration reported to induce apoptosis in cultured hippocampal neurons $(0.5 \mu \mathrm{M})$ [16]. In addition, for one patient with $\mathrm{BM}$, the $\mathrm{HCY}$ and CYS levels were measured in CSF samples collected at admission during the acute infection and after cure (HCY: 0.690 vs. $0 \mu \mathrm{M}$; CYS: 51.231 vs. $0 \mu \mathrm{M}$ ). These results indicate that the $\mathrm{HCY}$ and CYS levels were increased during acute $\mathrm{BM}$, dropping to normal levels after cure. No correlations were found between HCY or CYS levels and the standard CSF cytochemical parameters.

This is the first work reporting the association between increased HCY levels within the CNS and the pathophysiology of acute BM. The specific increase in $\mathrm{HCY}$ concentrations in the CSF of children with acute 
Table 1 Cytochemical parameters in the CSF of patients with meningitis and controls

\begin{tabular}{|c|c|c|c|c|c|c|}
\hline & \multicolumn{2}{|c|}{$\begin{array}{c}\text { BM } \\
(n=9)\end{array}$} & \multicolumn{2}{|c|}{$\begin{array}{c}\text { VM } \\
(n=13)\end{array}$} & \multicolumn{2}{|c|}{$\begin{array}{c}\text { Ctrl } \\
(n=18)\end{array}$} \\
\hline & $\begin{array}{c}\text { Mean } \pm \text { SD } \\
\text { (range) }\end{array}$ & Median & $\begin{array}{c}\text { Mean } \pm \text { SD } \\
\text { (range) }\end{array}$ & Median & $\begin{array}{c}\text { Mean } \pm \text { SD } \\
\text { (range) }\end{array}$ & Median \\
\hline \multirow[t]{2}{*}{$\mathrm{HCY}(\mu \mathrm{M})$} & $1.08 \pm 1.43$ & $0.69^{*{ }^{\dagger}}$ & 0 & $0^{*}$ & $0.05 \pm 0.16$ & $0^{\dagger}$ \\
\hline & $(0.0-4.37)$ & & $(-)$ & & $(0.0-0.52)$ & \\
\hline \multirow[t]{2}{*}{ CYS $(\mu \mathrm{M})$} & $30.77 \pm 18.46$ & $29.34^{*^{\dagger}}$ & $8.41 \pm 5.49$ & $8.19^{*}$ & $7.72 \pm 4.70$ & $8.33^{+}$ \\
\hline & $(13.37-67.64)$ & & $(0.0-19.92)$ & & $(0.0-16.48)$ & \\
\hline \multirow[t]{2}{*}{$\% \mathrm{PMN}$} & $77.89 \pm 27.86$ & $86^{*}$ & $35.92 \pm 37.38$ & 19 & $16.22 \pm 26.43$ & $3.5^{*}$ \\
\hline & $(5-95)$ & & $\mid(0-95)$ & & & \\
\hline \multirow[t]{2}{*}{$\mathrm{WBC} / \mu \mathrm{L}$} & $1383 \pm 2131$ & $120^{*}$ & $75.38 \pm 92.96$ & $50^{\dagger}$ & $4.05 \pm 4.10$ & $2.5^{*^{\dagger}}$ \\
\hline & $(18-5600)$ & & $(8-348)$ & & $(1-9)$ & \\
\hline \multirow[t]{2}{*}{ Protein (mg/dL) } & $157.83 \pm 136.1$ & $117^{*^{\dagger}}$ & $32.67 \pm 12.49$ & $26^{*}$ & $33.34 \pm 18.98$ & $26.15^{\dagger}$ \\
\hline & $(35-441)$ & & $(20-56.6)$ & & $(20-85)$ & \\
\hline \multirow[t]{2}{*}{ Glucose (mg/dL) } & $48 \pm 15.67$ & 48 & $53 \pm 19.62$ & 57.5 & $60.94 \pm 9.59$ & 60 \\
\hline & $(20-71)$ & & $(40-72)$ & & $(50-84)$ & \\
\hline
\end{tabular}

$\mathrm{BM}=$ bacterial meningitis; $\mathrm{VM}=$ viral meningitis; $\mathrm{Ctrl}=$ controls; $\mathrm{HCY}=$ homocysteine; $\mathrm{CYS}=$ cysteine; $\mathrm{WBC}=$ white blood cell; $\mathrm{PMN}=$ polymorphonuclear neutrophils; $\mathrm{SD}=$ standard deviation; ${ }^{*}$ or ${ }^{+}=\mathrm{p}<0.05$.

$\mathrm{BM}$, and the absence of correlation between HCY and CYS or the standard CSF cytochemical parameters indicate that the local production of $\mathrm{HCY}$ in the intrathecal space is part of the host response to the pneumococci or meningococci invasion of the CNS. The intrathecal accumulation of $\mathrm{HCY}$ at potentially neurotoxic levels [16] strongly support the hypothesis that this sulphur amino acid may play a pivotal role in the pathophysiological processes that lead to neuron death and brain damage associated with acute BM. In agreement with these conclusions, Qureshi et al. [19] have previously reported increased HCY levels in CSF samples of adults with tuberculous meningitis compared to those with aseptic meningitis or controls. However, these authors did not investigate HCY levels in children with acute BM. The HCY concentrations in adult patients with aseptic meningitis and control adults reported by Qureshi et al. were higher than those reported herein for children. This may be explained by the differences in the average age of the patients enrolled in these two studies. Indeed, previously reported reference values for $\mathrm{HCY}$ in the CSF from healthy adults ranged from 1.28 to $0.66 \mu \mathrm{M}$ [20], while for healthy children these reference values were lower than $0,10 \mu \mathrm{M}[21]$.

\section{Conclusions}

The results presented herein, in the light of the current biomedical literature, suggest that the excess of homocysteine within the central nervous system may play a pivotal role in the pathophysiology of acute bacterial meningitis. Further investigations with larger cohorts and additional studies using animal models are still needed in order to assess the association between increased HCY levels within the CNS and the development of brain damage and permanent neurological sequelae after acute BM. If this association can be definitely established, new adjuvant therapies to prevent brain damage in BM will be conceivable targeting key enzymes of the homocysteine pathway.

\section{Abbreviations}

BM: Bacterial meningitis; CNS: Central nervous system; CSF: Cerebrospinal fluid; CYS: Cysteine; HCY: Homocysteine; HPLC: High-performance liquid chromatography; NMDA: N-methyl-D-aspartate; PARP: Poly(ADP-ribose) polymerase; VM: Viral meningitis.

\section{Competing interests}

The authors declare that they have no competing interests.

\section{Authors' contributions}

RSC - conceived, designed and coordinated this study, did the biochemical and statistical analysis, and wrote the manuscript. BFAC - contributed significantly to the biochemical analysis and critically reviewed the manuscript. TMSC - recruited the patients, collected the samples and clinical data, and critically reviewed the manuscript. VD'A - contributed significantly to the experimental design, data analysis, and critically reviewed the manuscript. All authors read and approved the final manuscript.

\section{Acknowledgements}

This work received financial support from FAPEMIG, CNPq, FAPESP and AFIP.

\section{Author details}

${ }^{1}$ Biosystems Informatics, Research Center Rene Rachou, FIOCRUZ, Av. Augusto de Lima 1715, Belo Horizonte, MG Zip Code: 30190-002, Brazil. ${ }^{2}$ Department of Psychobiology, Universidade Federal de São Paulo (UNIFESP/EPM), São Paulo, SP, Brazil. ${ }^{3}$ Children's Hospital João Paulo II FHEMIG, Belo Horizonte, MG, Brazil.

Received: 10 July 2014 Accepted: 12 November 2014 Published: 22 November 2014 


\section{References}

1. Somand D, Meurer W: Central nervous system infections. Emerg Med Clin North Am 2009, 27(1):89-100. ix.

2. Bedford H, de Louvois J, Halket S, Peckham C, Hurley R, Harvey D: Meningitis in infancy in England and Wales: follow up at age 5 years. BMJ 2001, 323(7312):533-536.

3. Gerber J, Brück W, Stadelmann C, Bunkowski S, Lassmann H, Nau R: Expression of death-related proteins in dentate granule cells in human bacterial meningitis. Brain Pathol 2001, 11(4):422-431.

4. Nau R, Soto A, Brück W: Apoptosis of neurons in the dentate gyrus in humans suffering from bacterial meningitis. J Neuropathol Exp Neurol 1999, 58(3):265-274

5. Gianinazzi C, Grandgirard D, Imboden H, Egger L, Meli D, Bifrare $Y$, Joss $P$, Tauber M, Borner C, Leib S: Caspase-3 mediates hippocampal apoptosis in pneumococcal meningitis. Acta Neuropathol 2003, 105(5):499-507.

6. Koedel U, Winkler F, Angele B, Fontana A, Pfister H: Meningitis-associated central nervous system complications are mediated by the activation of poly(ADP-ribose) polymerase. J Cereb Blood Flow Metab 2002, 22(1):39-49.

7. Finkelstein J: The metabolism of homocysteine: pathways and regulation. Eur J Pediatr 1998, 157(Suppl 2):S40-S44.

8. Lipton S, Kim W, Choi Y, Kumar S, D'Emilia D, Rayudu P, Arnelle D, Stamler J: Neurotoxicity associated with dual actions of homocysteine at the N-methyl-D-aspartate receptor. Proc Natl Acad Sci U S A 1997, 94(11):5923-5928.

9. Pullan L, Olney J, Price M, Compton R, Hood W, Michel J, Monahan J: Excitatory amino acid receptor potency and subclass specificity of sulfur-containing amino acids. J Neurochem 1987, 49(4):1301-1307.

10. Outinen P, Sood S, Liaw P, Sarge K, Maeda N, Hirsh J, Ribau J, Podor T, Weitz J, Austin R: Characterization of the stress-inducing effects of homocysteine. Biochem J 1998, 332(Pt 1):213-221.

11. Huang R, Huang S, Lin B, Wei J, Liu T: Homocysteine thiolactone induces apoptotic DNA damage mediated by increased intracellular hydrogen peroxide and caspase 3 activation in HL-60 cells. Life Sci 2001, 68(25):2799-2811.

12. Leib S, Kim Y, Ferriero D, Tauber M: Neuroprotective effect of excitatory amino acid antagonist kynurenic acid in experimental bacterial meningitis. J Infect Dis 1996, 173(1):166-171.

13. Kolarova A, Ringer $R$, Tauber M, Leib S: Blockade of NMDA receptor subtype NR2B prevents seizures but not apoptosis of dentate gyrus neurons in bacterial meningitis in infant rats. BMC Neurosci 2003, 4:21.

14. Gerber J, Nau R: Mechanisms of injury in bacterial meningitis. Curr Opin Neurol 2010, 23(3):312-318.

15. Blount B, Mack M, Wehr C, MacGregor J, Hiatt R, Wang G, Wickramasinghe $S$, Everson R, Ames B: Folate deficiency causes uracil misincorporation into human DNA and chromosome breakage: implications for cancer and neuronal damage. Proc Natl Acad Sci U S A 1997, 94(7):3290-3295.

16. Kruman I, Culmsee C, Chan S, Kruman Y, Guo Z, Penix L, Mattson M: Homocysteine elicits a DNA damage response in neurons that promotes apoptosis and hypersensitivity to excitotoxicity. J Neurosci 2000, 20(18):6920-6926.

17. Negrini B, Kelleher K, Wald E: Cerebrospinal fluid findings in aseptic versus bacterial meningitis. Pediatrics 2000, 105(2):316-319.

18. Pfeiffer C, Huff D, Gunter E: Rapid and accurate HPLC assay for plasma total homocysteine and cysteine in a clinical laboratory setting. Clin Chem 1999, 45(2):290-292.

19. Qureshi G, Baig S, Bednar I, Halawa A, Parvez S: The neurochemical markers in cerebrospinal fluid to differentiate between aseptic and tuberculous meningitis. Neurochem Int 1998, 32(2):197-203.
20. Hyland K, Bottiglieri T: Measurement of total plasma and cerebrospinal fluid homocysteine by fluorescence following high-performance liquid chromatography and precolumn derivatization with o-phthaldialdehyde. J Chromatogr 1992, 579(1):55-62.

21. Surtees $\mathrm{R}$, Bowron A, Leonard J: Cerebrospinal fluid and plasma total homocysteine and related metabolites in children with cystathionine beta-synthase deficiency: the effect of treatment. Pediatr Res 1997 , 42(5):577-582.

doi:10.1186/1472-6890-14-43

Cite this article as: Coimbra et al:: A putative role for homocysteine in the pathophysiology of acute bacterial meningitis in children. BMC

Clinical Pathology 2014 14:43.

\section{Submit your next manuscript to BioMed Central and take full advantage of:}

- Convenient online submission

- Thorough peer review

- No space constraints or color figure charges

- Immediate publication on acceptance

- Inclusion in PubMed, CAS, Scopus and Google Scholar

- Research which is freely available for redistribution

Submit your manuscript at www.biomedcentral.com/submit
C BioMed Central 